\title{
Maxillofacial Trauma: An Unexpected Means in the Diagnosis of Eagle Syndrome- A Case Report
}

Hamza Hassan Mirza, BDS, MDS (Resident)* , Faheem Ahmed, BDS, FCPS (Resident), Zahoor Ahmed Rana, BDS, MDS

Department of Oral and Maxillofacial Surgery, Pakistan Institute of Medical Sciences

DOI: $10.36347 /$ sjmcr.2020.v08i07.007

| Received: 02.07.2020 | Accepted: 09.07.2020 | Published: 18.07.2020

*Corresponding author: Dr. Hamza Hassan Mirza, BDS, MDS

\section{Abstract}

Eagle syndrome is a rare condition that is difficult to diagnose due to the myriad of non-specific symptoms related to orofacial and cervical region and is a result of an abnormal elongation of styloid process causing compression of surrounding nerves or vessels. Patient can present with oropharyngeal, cervical, temporomandibular or auricular pain, globus sensation, dysphagia, transient ischemic attack and syncope. Diagnosis is established by correlating the symptoms with radiologic confirmation. This case report depicts a 50 year old male patient who reported with multiple facial fractures. His radiographs showed a markedly elongated styloid process of the right side and his medical history revealed that he experienced mild dysphagia, transient voice changes and right sided jaw pain occasionally and hence the diagnosis of Eagle syndrome was confirmed during the evaluation of maxillofacial injuries.

Keywords: Eagle syndrome, elongated styloid process, oropharyngeal pain, facial fractures.

Copyright @ 2020: This is an open-access article distributed under the terms of the Creative Commons Attribution license which permits unrestricted use, distribution, and reproduction in any medium for non-commercial use (NonCommercial, or CC-BY-NC) provided the original author and source are credited.

\section{INTRODUCTION}

The rare disorder comprising of a complex of symptoms caused by elongation of styloid process and/or mineralization of stylohyoid complex was first described by Watt Eagle in 1937 and is known as Eagle syndrome [1]. The normal length of styloid process is around $2.5-3 \mathrm{~cm}$. Elongation above $3 \mathrm{~cm}$ is considered abnormal and can result in a wide spectrum of unpleasant symptoms characterized in eagle syndrome. The elongation can be unilateral or bilateral. However, symptoms are generally unilateral [2]. An elongated styloid process is found in about $4 \%$ of the general population. The majority of affected persons is asymptomatic and is diagnosed after an incidental finding on radiographs. Symptoms develop in 4-10\% of people with an elongated styloid process and are due to impingement or compression of adjacent structures. The etiology of this rare anomaly is not yet known [3].

Symptoms are usually non-specific and vary widely among people. This is due to compression of any of the adjacent structures mainly cranial nerves $\mathrm{V}$, VII, IX, X, internal carotid artery and perivascular sympathetic fibers. Patient can present with pharyngeal symptoms such as dysphagia, odynophagia, foreign body sensation, transient voice changes and pain on turning the head. Pain can radiate to the jaw or ear. In rare cases, syncope or transient ischemic event can also ensue as a result of compression of carotid arteries [4].

Eagle syndrome is difficult to diagnose clinically as the symptoms are variable and mimic other diseases. The diagnosis is confirmed by imaging. Several radiographs have been employed such as panoramic view and lateral cephalometry but CT scan has proven the most accurate as it allows 3D visualization and exact measurement of the length of styloid process [5].

\section{Case Report}

A 50 year old male patient reported to the department of Oral and Maxillofacial Surgery, Pakistan Institute of Medical Sciences (PIMS) with multiple facial fractures secondary to a road traffic accident. Patient was admitted to the ward. Medical history revealed that the patient was a known type 2 diabetic with poor glycemic control. Apart from that, he had previous complaints of mild dysphagia, voice changes and right sided jaw pain (VAS score of 4) occasionally which had exacerbated after trauma. Family history was not significant. 
CT scan with 3D reformatting was carried out for radiographic evaluation which showed fracture of anterior right mandible, bilateral maxilla and zygoma, nasoethmoidal complex and hard palate (Figure 1). Moreover, the CT scan clearly showed a markedly elongated styloid process of the right side measuring approx. $6.5 \mathrm{~cm}$ in length and $7.93 \mathrm{~mm}$ in anteroposterior and mesiodistal dimensions and after correlating with the patient's previous symptoms, the diagnosis of Eagle syndrome was established (Figure 2, $3,4,5)$. The elongated styloid process could not be palpated clinically in the tonsillar fossa due to post traumatic edema.

The patient was explained about the treatment options of his Eagle's syndrome that is surgical styloidectomy and medical treatment. The patient did not give consent for styloidectomy as he only had mild symptoms and opted for pharmaceutical therapy. The patient underwent open reduction and internal fixation under general anesthesia for midfacial and mandibular fractures. Patient recovered uneventfully from GA and was discharged on gabapentin and acetaminophen. Follow-up was done and the patient reported a marked decrease in symptoms after 3 months of treatment.

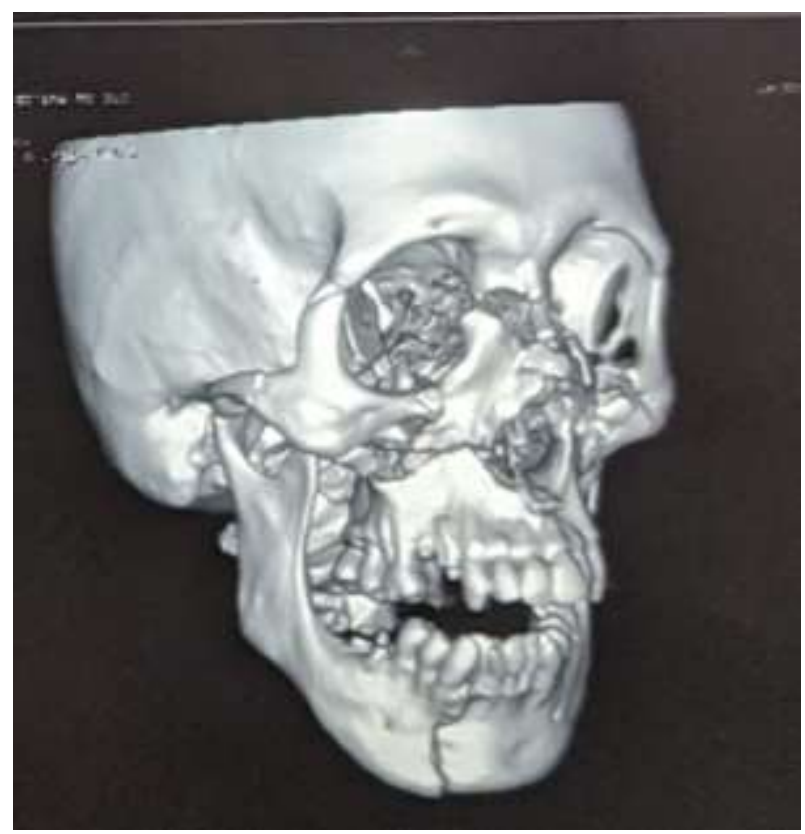

Fig-1: 3D CT scan showing maxillofacial fractures

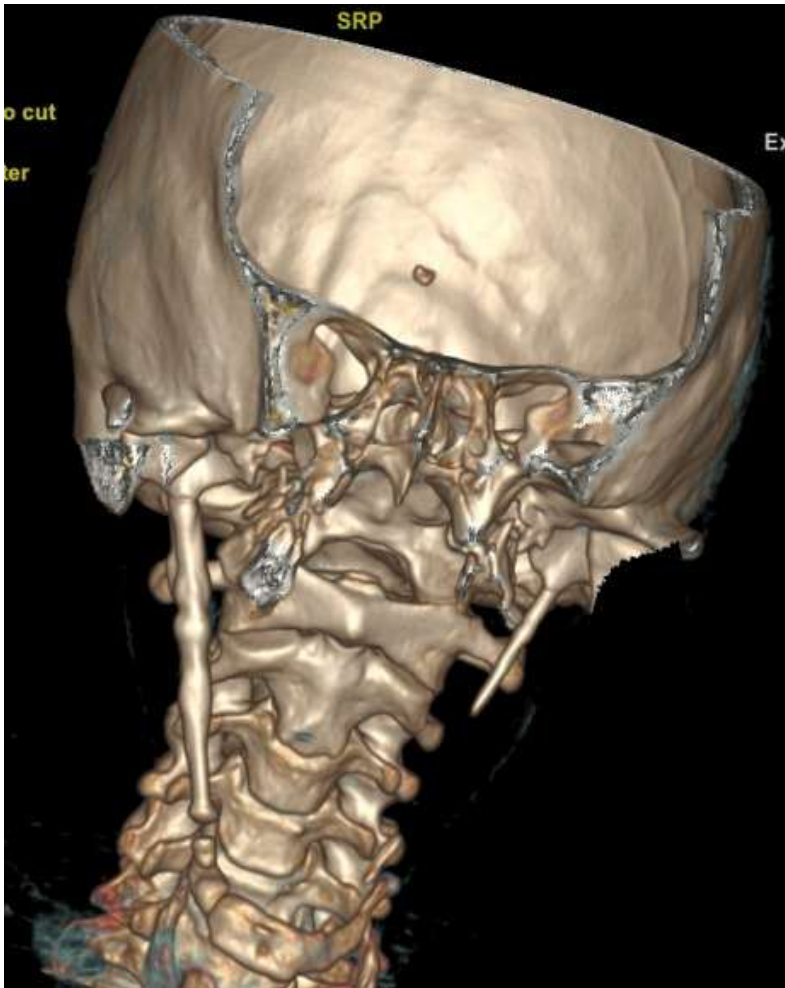

Fig-2: 3D model showing elongated styloid process

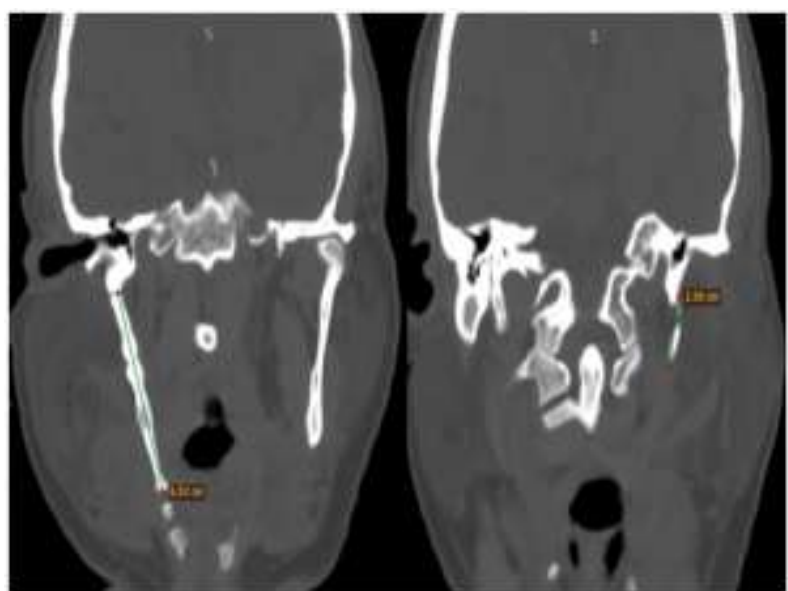

Fig-3: Length of styloid processes of right and left side

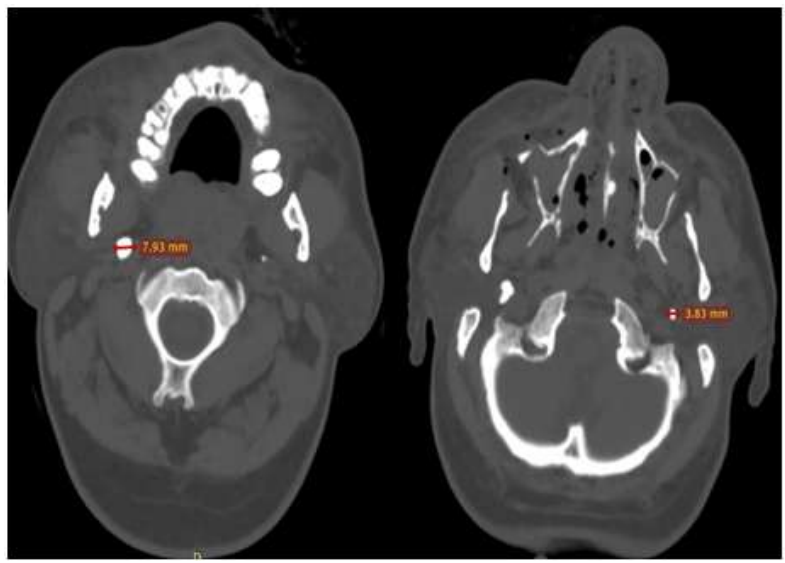

Fig-4: Mesiodistal dimensions of right and left styloid processes 


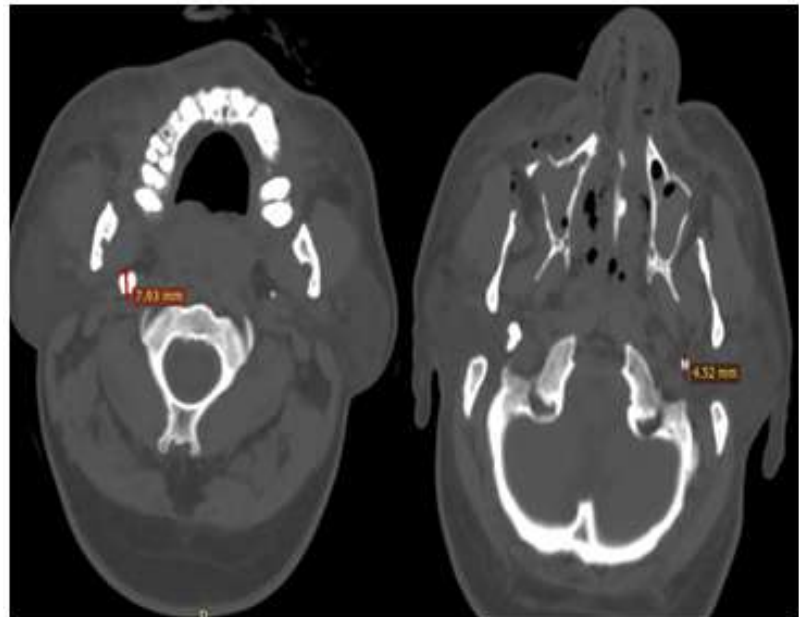

Fig-5: Anteroposterior dimensions of right and left styloid processes

\section{DiscuSSION}

Eagle syndrome is an aggregation of symptoms caused by abnormal elongation of the temporal styloid process leading to compression or irritation of surrounding neurovascular structures. Watt eagle detailed two groups for this syndrome based on the symptoms. The first or classic Eagle syndrome is caused by ossification stylohyoid complex forming scar tissue compressing the cranial nerves V, VII, IX or X and causing pain in their proximity. It can present as dysphagia, dysphonia, painful swallowing, feeling of something stuck in throat, pain in neck on flexing or turning or referred pain to the jaw and otalgia[5,6].

The second type is also known as stylocarotid syndrome. In this type elongation or deviation of styloid process causes compression of external or internal carotid artery which can manifest as syncopal episode on turning the head, transient ischemic attack, aphasia, visual disturbance or pseudoaneurysm. Episodes of migraine or cluster headache can also occur due to sympathetic plexus stimulation[4,7].

Elongation of styloid process is predominantly asymptomatic and produces symptoms in only $4-10 \%$ of people with this anomaly. Females are affected more often than males and average age of presentation is 43 years. The pathogenesis of this disorder is still unknown. Most cases are diagnosed incidentally on radiographic imaging done for other suspected diseases[3,8]. The patient in this case report was also mildly symptomatic and was diagnosed incidentally through CT scan which was employed for the detection of maxillofacial fractures.

The differential diagnosis for Eagle syndrome is vast. The non-specific orofacial or cervical pain can resemble trigeminal, glossopharyngeal or sphenopalatine neuralgias, temporomandibular joint or myofascial pain, otitis, cervical arthralgias, pharyngitis and neoplastic diseases. Misdiagnoses are common and patients are usually referred to neurologists, otolayngologists, maxillofacial surgeons, dentists or even psychiatrists owing to the nature of symptoms[9].

The management of Eagle syndrome depends on the degree of severity of patient's symptoms. Both pharmaceutical and surgical options can be employed. Non-steroidal anti-inflammatory drugs, anticonvulsants e.g carbamazepine, gabapentin, valproate or psychotropics such as amitriptyline can be given. Taheri et al. proclaimed an $80 \%$ reduction in symptoms after 6 months of therapy with pregabalin $(75 \mathrm{mg}$ daily) and amitriptyline (10 mg daily)[4]. Transpharyngeal steroid injections have also been given to treat the symptoms [10]. Surgical removal of the elongated portion of styloid process has been successful in providing long lasting relief through decompression of the irritated nerves. This can be accomplished by transcervical approach which provides adequate surgical exposure and minimal risk of surgical site infection. However, it is time consuming and leaves a visible postoperative scar. The transpharyngeal approach is short and does not leave external scar but its main disadvantages are risk of deep cervical infection, inadequate surgical field visualization, difficulty in achieving hemostasis and postoperative edema [11]. Endoscope assisted transoral approaches and transoral robotic surgeries are now becoming increasingly popular with satisfactory visualization and minimal hazards [12].

\section{CONCLUSION}

The diagnosis of Eagle syndrome requires thorough history of the nature and duration of symptoms along with clinical examination and radiologic confirmation and ruling out other more common cervicofacial disorders so it can be managed in the most effective way.

\section{Conflict of interest}

The authors declare that there is no conflict of interest

\section{Ethics Approval}

This case report is submitted for publication after taking written informed consent from the patient for his information and images to be published and after taking approval from Institutional Review Board, IRB No. F.1-1/2015/ERB/SZABMU/573

\section{Acknowlegements}

The authors would like to thank Dr. Shahab Siddiqui from the Radiology department for his assistance

\section{REFERENCES}

1. Zeckler S-R, Betancur AG, Yaniv G. The eagle is landing: Eagle syndrome-an important differential diagnosis. $\mathrm{Br} \mathrm{J}$ Gen Pract. 2012;62(602):501-502. 
2. Ferreira PC, Mendanha M, Frada T, Carvalho J, Silva Á, Amarante J. Eagle syndrome. Journal of Craniofacial Surgery. 2014;25(1):e84-e86.

3. Hossein R, Kambiz M, Mohammad D, Mina N. Complete recovery after an intraoral approach for Eagle syndrome. Journal of Craniofacial Surgery. 2010;21(1):275-276.

4. Badhey A, Jategaonkar A, Kovacs AJA. Eagle syndrome: a comprehensive review. Clinical neurology and neurosurgery. 2017;159:34-38.

5. Bokhari MR, Graham C, Mohseni M. Eagle syndrome. StatPearls [Internet]: StatPearls Publishing; 2019.

6. Jewett J, Moriarity R. Eagle syndrome: an incidental finding in a trauma patient: a case report. The Journal of emergency medicine. 2014;46(1):e9-e12.

7. Radak D, Tanaskovic S, Kecmanovic V, Babic S, Popov P, Gajin P. Bilateral Eagle syndrome with associated internal carotid artery kinking and significant stenosis. Annals of vascular surgery. 2016; 34:271. e215-271. e218.

8. Maher T, Shankar H. Ultrasound- Guided Peristyloid Steroid Injection for Eagle Syndrome. Pain Practice. 2017;17(4):554-557.

9. Koivumäki A, Marinescu-Gava M, Järnstedt J, Sándor G, Wolff J. Trauma induced eagle syndrome. International journal of oral and maxillofacial surgery. 2012;41(3):350-353.

10. Scheller K, Eckert AW, Scheller C. Transoral, retromolar, para-tonsillar approach to the styloid process in 6 patients with Eagle's syndrome. Medicina oral, patologia oral y cirugia bucal. 2014;19(1):e61.

11. Khawja AQ, Bhatti WJ, Jameel K. Eagles Syndrome. Ann. Pak. Inst. Med. Sci. 2013;9(3):164-166.

12. Montevecchi F, Caranti A, Cammaroto G, Meccariello G, Vicini C. Transoral robotic surgery (TORS) for bilateral Eagle syndrome. ORL. 2019;81(1):36-40. 